\title{
The Stigma of Mental Illness in the Labor Market
}

\author{
ABSTRACT \\ Mental illness labels are accompanied by devaluation and discrimination. We extend research on \\ reactions to mental illness by utilizing a field experiment $(\mathrm{N}=635)$ to test effects of mental illness \\ labels on labor market discrimination. This study involved sending fictitious applications to job \\ listings, some applications indicating a history of mental illness and some indicating a history of \\ physical injury. In line with research indicating that mental illness leads to stigma, we predicted \\ fewer callbacks to candidates with mental illness. We also predicted relatively fewer callbacks \\ for applicants with mental illness when the jobs involved a greater likelihood for interpersonal \\ contact with the employer. Results showed significant discrimination against applicants with \\ mental illness, but did not indicate an effect of potential proximity to the employer. This \\ contributes a valuable finding in a natural setting to research on labor market discrimination \\ towards people with mental illness.
}




\section{The Stigma of Mental Illness in the Labor Market INTRODUCTION}

The stigmatization that accompanies mental illness diagnoses is well documented. A label of mental illness engenders broadly negative stereotypes, adverse treatment in interactions, avoidance by others, and various forms of discrimination (e.g., Page and Day 1990; Phelan 2005). A body of research on the stigmatization of mental illness focuses on perceptions of those who have been stigmatized (stigma targets), finding that those with mental illness diagnoses generally believe that they face negative treatment based on their illnesses. Much research also addresses attitudes of those who perpetuate stigma - whether consciously or subconsciously, such as research on public perceptions of mental illness. Less commonly, research focuses on the interactional processes in which stigmatization occurs. Research focusing on interactions (e.g., Farina and Ring 1965; Farina and Felner 1973; Lucas and Phelan 2012; Sibicky and Dovidio 1986) has also found that mental illness diagnoses are accompanied by stigmatization.

The labor market is one interactional setting in which discrimination can have profound implications. Evidence of discrimination in the labor market against persons with mental illness labels is indicated in higher rates of unemployment and underemployment for persons with mental illness labels than the general population (Baldwin and Marcus 2007; Cook 2006; Stuart 2004). Individuals suffering from mental illness also report being passed over for jobs for which they were qualified, demoted, or fired as a result of their mental illnesses (Cook 2006; Corrigan 2003; Stuart 2004). Further, employers explicitly express negative attitudes regarding workers with mental illness and may be hesitant to hire them (Cook 2006; Scheid 1998; Stuart 2004). These findings are suggestive of discrimination toward people with mental illness but do not explicitly test this process. 
Employment discrimination is difficult to directly demonstrate. In part because such discrimination is illegal, employers are unlikely to say they discriminate against persons with mental illnesses. Further, persons with mental illnesses will rarely have direct knowledge of discrimination against them, because the reasons for a failed application are seldom known. Approaches to identifying discrimination, such as comparing the employment rates of mentally ill and other persons, suggest labor market discrimination but are difficult to interpret because of the large number of potentially confounding variables.

Field experiments are a uniquely valuable tool for identifying employment discrimination because they measure behavioral outcomes in actual employment situations. This approach has been fruitful in documenting discrimination in employment, housing, and other settings. However, such designs have rarely been used to study discrimination against persons with mental illness (Brand and Claiborn 1976; Farina and Felner 1973; Page and Day 1990). We describe what to our knowledge is the first field experiment using a national sample of employers on the website Craigslist to assess the stigmatizing effects of mental illness labels on discrimination in the labor market. In our study, we systematically test for hiring discrimination based on a mental illness label, holding the candidate's qualifications constant.

\section{THEORETICAL FRAMEWORK}

Mental illness, more than any other social attribute, has been widely identified as stigmatizing (Phelan, Link and Dovidio 2008). Stigma is a process that occurs when people make distinctions and assign labels to individuals; certain characteristics are deemed undesirable; a division is created between labeled/non-labeled people; and a power differential exists that allows for stigmatization to occur (Link and Phelan 2001). Studies typically examine the stigma 
process from the point of view of the stigma targets or individuals who perpetuate stigma. Research on stigma targets finds that persons with mental illness believe they face social rejection due to their condition, and as a result use various strategies to cope with and adapt to the stigmatization (Fife and Wright 2000; Goffman 1963; Link et al. 1989; Ritsher and Phelan 2004; Rosenfield 1997; Sirey et al. 2001). From the stigmatizers' perspective, studies have focused on the stereotypes associated with mental illness labels and the consequences of these beliefs (Corrigan 2000; Fife and Wright 2000; Link et al. 1999; Martinez et al. 2011; Weiner, Perry and Magnusson 1988). We are aware of few studies that have examined interactions occurring between stigmatizers and stigma targets (Farina and Ring 1965; Farina and Felner 1973; Lucas and Phelan 2012; Sibicky and Dovidio 1986), and the stigma literature has been critiqued for having an overly individualistic focus (Hebl and Dovidio 2005; Link et al. 2004). Our study represents a contribution to this small body of interaction-focused research by focusing on relationships between job applicants and persons making callback decisions.

\section{Stigmatization and Discrimination}

Stigma is a social process rooted in norms and structured toward creating unequal outcomes. One outcome of the stigma process that may perpetuate negative treatment of individuals with mental illness is the awkwardness that arises in interactions between stigmatized and non-stigmatized persons (Goffman 1963; Hebl, Tickle, and Heatherton 2000). This awkwardness may arise from the anxiety caused by believing the stigmatized person is dangerous, the uncertainty of interacting with the person, or a potential violation of norms (Hebl et al. 2000). For these reasons, some employers may be hesitant to contact applicants who indicate a history of mental illness, especially if they foresee having to interact with the person

on a regular basis in an office setting. Krupa et al. (2009) examined work-related stereotypes for 
people with mental illness, finding that co-workers may believe the person is incompetent, dangerous, and she or he is not fit to hold a job. Such stereotypes render people with mental illness as distinct and less worthy than workers with no mental illness labels.

The culmination of the stigma process is discrimination and diminished life chances for individuals labeled as mentally ill. The stigma of mental illness leads to demoralization, decreased social support, lowered self-esteem, reduced desire to seek help, and unemployment (Link 1987; Link et al. 1989; Ritsher and Phelan 2004; Sirey et al. 2001). Furthermore, mental illness labels lead to negative treatment in interactions, social rejection, and discrimination in several social sectors including employment, health care, and housing (Brand and Claiborn 1976; Druss et al. 2000; Farina and Felner 1973; Link et al. 1987; Link et al. 1999; Page and Day 1990; Phelan 2005; Sibicky and Dovidio 1986).

Past studies have utilized audit methodologies to assess discrimination toward people with mental illness. Audit studies incorporate experimental methods in real-life settings to isolate social characteristics and test for discrimination (Correll et al. 2007). However, past audit studies on our topic were much smaller in scale than allowed by modern methods. Farina and Felner's (1973) study of employer discrimination against people with mental illness had a sample size of 32, while Brand and Claiborn's (1976) audit of job interviews had a sample size of 36 . In contrast, our study involved sending out 635 applications, which we believe provides us a greater ability to perform analyses on data drawn from a large, geographically diverse sample and also to determine the extent to which findings from roughly four decades ago still hold today.

\section{PREDICTIONS}


Following research indicating that mental illness is accompanied by various forms of devaluation and discrimination, we predict that mental illness history will lead to hiring discrimination and that a desire for social distance from people with mental illness will moderate this effect. Reflecting the stigma that accompanies mental illness labels, we predicted that applicants indicating a history of mental illness would be less likely to receive callbacks than other applicants:

Hypothesis 1: Applicants with a history of mental illness will receive fewer callbacks from employers than applicants with a history of physical injury.

We also varied whether the jobs to which we applied would or would not involve being able to work away from the office. Hiring discrimination based on mental illness labels may be partially due to fear of or anxiety about personally interacting with the person with mental illness, such as in an office setting (Premeaux 2001). Should the job be a telecommuting position - which can be done away from an office - the applicant's disclosure of mental illness may be less likely to elicit discrimination. We predict that:

Hypothesis 2: The location of the job - whether performed in an office or away from an office - will moderate the negative effect of mental illness on the applicant's chances of being called back, such that the negative effect of mental illness on an applicant's chances of being called back will be lower if the job may be performed away from the office.

\section{METHODS}


We sent applications that differed on the reason the candidate had been absent from work for six months and whether the job could be performed mostly away from an office, using the popular online classified posting website Craigslist. The fictitious applicant was a man who was well-qualified for both software engineering and software design positions (see Appendix A for the resume). We asked two computer specialists to assist in crafting the resume, and made the candidate a graduate of a prestigious computer science program with honors, and a past employee as both software engineer and developer at competitive employers. Resumes were identical across conditions except for the contact email and phone number, which were linked accounts set up for each of the experimental conditions. The candidate's ethnic background was ambiguous. We focused narrowly on one field and one sex for this initial investigation to maximize our likelihood of finding discrimination if it existed. Conditions for this study are as follows:

Condition 1: The candidate had a history of mental illness and was applying for a standard job posting.

Condition 2: The candidate had a history of mental illness and was applying for a job that could be done mostly from home.

Condition 3: The candidate had a history of physical injury and was applying for a standard job posting.

Condition 4: The candidate had a history of physical injury and was applying for a job that could be done mostly from home.

What we call our control condition involved the target missing work for an extended time because of a physical injury from which he had fully recovered. We felt that some explanation for the extended absence was necessary, and we believed that missing work for a major injury 
from which one has recovered would not lead to stigmatization. One concern is that persons might discriminate against a person who suffered a physical injury. Although an injury from which a person has recovered is of course not the same as a physical disability, research has found employment discrimination against persons with disabilities (Ameri et al. 2015). If respondents in our sample did in fact discriminate against persons with physical injuries, the result would be a conservative estimate of the consequences of mental illness.

\section{Field Experiments as Tests of Discrimination}

Our goal was to test the effects of mental illness labels in the labor market. Experimental studies conducted in real labor markets, such as audit studies or field experiments, are the only way to allow for the isolation of key traits in order to assess their impact on hiring. Such studies may serve as tests of whether certain social attributes lead to discrimination in natural settings.. For example, recent studies have documented discriminatory hiring practices based on race, motherhood, and sexuality (Bertrand and Mullainathan 2003; Pager and Quillian 2005; Correll et al. 2007; Tilcsik 2011). Our method represents the only practical way to assess true, meaningful discrimination against people with mental illness in a large, geographically diverse labor market.

Reflective of the increase in social interactions taking place via online communication, at least three recent studies have involved experiments using online postings: Bertrand and Mulllainathan assessed the level of candidates' employability based on their name; Lauster and Easterbrook (2011) recently used an online field experiment to demonstrate housing discrimination against same-sex couples in Canada; and Tilcsik (2011) tested for prejudice toward openly gay job applicants with emailed applications. Thus, the rise in the number of social exchanges taking place online has facilitated the application of sociological methods to 
large-scale experiments in natural settings. Such experiments are reflective of the modern hiring process, which is often done via email and other online exchanges.

Our methodology combines standard experimental methods with a large, geographically diverse sample. While standard laboratory experiments allow for a thorough, controlled test of stigma mechanisms, our approach allows for a test among a sample of real employers in a natural setting. We used a large, free online classified advertisement website through which employers conduct job searches. The website is well organized such that particular labor fields may be easily sorted and searched. Furthermore, the website organizes jobs by whether they allow employees to telecommute. This allowed us to have a sample of jobs for which we could expect our candidate to be more physically separated from other employees. To conduct the experiment, we created email and voicemail accounts for fictitious applicants. Researchers followed a protocol to randomly determine which application would be sent to which position, as well as which city would be searched for job listings on a given day.

Some audit studies have sent matched pairs of applicants to apply to positions, either in person or via another application method. Matched pairs allow for high levels of confidence that one characteristic alone produced any unequal callback rates. Our study did not employ matched pairs of resumes for several reasons. First, because our fictitious applicant has either suffered from a physical injury or mental illness, sending two applications per job might arouse suspicion. Second, we did not want to artificially inflate demand for the jobs more than necessary to complete the study, as some positions required an extensive skillset and may have had very few applicants. Finally, by carefully controlling for details of the posts (e.g. length of time elapsed between the original post and the date we applied), we believe we have ensured necessary consistency across conditions without using matched pairs. Our method of using a 
large sample of job posts and sending single electronic inquiries to each is similar to that of Lauster and Easterbrook (2011), who examined discrimination in the housing market against same-sex couples and single parents without using matched pairs.

\section{Procedure}

To convey a history of mental illness or physical injury, each resume indicated an absence from work during the six months immediately preceding the month we applied to the position. We created a cover letter that explained the applicant's absence from work as due to either a hospitalization for a mental illness or physical injury. In both scenarios, the candidate stated that he had fully recovered from his illness.

We explained the absence in the following way:

\section{Conditions 1 and 3:}

“As you will see on my resume, I have not been working since [DATE]...

I was hospitalized for mental health treatment. The issues that led to my treatment are behind me, and I look forward to again beginning full-time employment."

\section{Conditions 2 and 4:}

"As you will see on my resume, I have not been working since

[DATE]..., I suffered a serious physical injury and had an extended hospital stay and recovery. The issues that led to my hospitalization are behind me, and I look forward to again beginning full-time employment.

\section{Sample}


For all conditions, we scanned job postings on Craigslist to ensure that our fictitious candidate was well-qualified for the position, as indicated on his resume. Due to the relative abundance of non-telecommuting jobs compared to telecommuting jobs, we sampled from the non-telecommuting positions based on the time that had elapsed since the original posting. This ensured that the conditions did not differ by length of time between posting and our application. To vary anticipated interpersonal contact, for two conditions we applied to jobs that could explicitly be performed via telecommuting for a substantial portion of the work hours. We scanned postings to ensure they explicitly mentioned that the job could be completed mostly by telecommuting. Finally, we indicated the candidate's desire to telecommute in the cover letters for these positions. We filtered job listings by whether they allowed for a significant amount of work to be done out of the office. We only applied to jobs for which we were confident that our fictitious applicant was well-qualified, based on the skills and past work experience represented on his resume. Furthermore, to maintain consistency we only applied to positions that allowed us to email in a resume and cover letter, rather than sending in hard copies or filling out an online application form. Both of these criteria led to approximately $80 \%$ of postings being inappropriate for our applications. Identical procedures were used for non-telecommuting and telecommuting positions. We emailed resumes and cover letters in response to 635 jobs from June 2011 to May 2012. We sampled jobs from among 22 markets. Table 1 shows the number of applications we sent by market. ${ }^{1}$

\section{[TABLE 1 ABOUT HERE]}

\footnotetext{
${ }^{1}$ Our sample provides us approximately $80 \%$ power for the main effects but clearly insufficient power for identifying local labor market differences. It is for this reason that we make no predictions about labor market effects, and instead control for them in our analysis.
} 
The relatively scarce number of jobs allowing for telecommuting limited our ability to complete data selection for the two telecommuting conditions more quickly.

We did not send applications in matched pairs of resumes for several reasons. First, since our fictitious applicant has either suffered from a physical injury or mental illness, sending two applications per job might arouse suspicion. Second, we did not want to artificially inflate demand for the jobs more than necessary to complete the study, and some positions may have had very few applicants. Third, the difficulty in pre-testing multiple resumes in a high-tech field to ensure similar levels of status would have been unnecessarily difficult. Finally, by controlling for details of all posts, we believe we have ensured necessary consistency across conditions without using matched pairs.

We recorded any employer responses that expressed interest in our candidate as callbacks. Due to the large numbers of phone calls that simply asked for the candidate to call back, we use a liberal method of recording callbacks, as we could often not be certain of the intent of the employer's call. Employers asking our candidate to call them back, asking the candidate for more information (such as specific skill-based questions), or specifically inviting him to a phone or in-person interview were all defined as callbacks.

As a final check on the consistency of our procedure across conditions, for each application we recorded whether there was any uncertainty in whether our candidate was qualified for a position (e.g. a certain skill not listed on the resume). The frequency of these uncertain applications was consistent across conditions (results available upon request).

\section{RESULTS}


Table 2 displays callback rates across conditions. Reflecting the impressive credentials of our fictitious applicant, our callback rates were above $20 \%$ for applicants with no history of mental illness. Other studies with similar methods report much lower callback rates. For example, both Kleykamp (2009) and Tilcsik (2011) reported callback rates of below $10 \%$ in their studies of veteran and openly gay job applicants, respectively. Consistent with our predictions, the conditions in which the candidate has a history of mental illness received fewer callbacks than conditions in which the candidate had a physical injury. Overall, $14.81 \%$ of our fictitious candidates with a history of mental illness received callbacks, compared to $21.86 \%$ of candidates with a history of physical injury. This difference is statistically significant $(\mathrm{z}=-2.31$;

$\mathrm{p}=.021$ ).Due to their scarcity relative to non-telecommuting positions, telecommuting jobs were much more competitive, and we received fewer callbacks across both conditions for these types of jobs. Mean differences indicate that the effect of having a history of mental illness decreased callback chances across both telecommuting and non-telecommuting jobs. We found significantly more callbacks for applicants with physical injuries than applicants with a mental illness ( $\mathrm{p}=.048$ ) when only looking at telecommuting positions, but a non-significant difference in callback rates $(\mathrm{p}=.160)$ for non-telecommuting jobs. This might reflect the higher level of competition for telecommuting positions, although our data only allow us to speculate on this.

\section{[TABLE 2 ABOUT HERE]}

Table 3 presents results of a logistic regression predicting the odds of an application receiving a callback based on whether the candidate had been hospitalized for a mental illness, whether the position allowed for telecommuting, the days between the initial job posting and our application, and the job locations. To account for different chances of receiving a callback across location we controlled for job location, using the city with the most applications (San Francisco) 
as the reference category. ${ }^{2}$ Twenty cases were omitted because their locations had no variation in callback rate. Results are presented in table 3.

\section{[TABLE 3 ABOUT HERE]}

The model shows a statistically significant $(\mathrm{p}=.006)$ independent effect of mental illness on callback rates, supporting Hypothesis 1, which predicted lower callbacks for the candidates with mental illness than candidates with a physical injury. Candidates with a history of mental illness - compared to those with a history of physical injury - were $45.6 \%$ less likely to elicit callbacks, controlling for other variables in the model. In Model 2, the interaction effect - that the effect of mental illness on being called back depends on whether the job takes place mostly away from an office - was not significant $(\mathrm{p}=.539)$. Additionally, a Wald test indicated that the coefficient for the interaction effect was not statistically different from zero. Thus, we do not find support for Hypothesis 2, which predicted an effect of social distance from the employer on callback rates. We report findings based on Model 1 which does not include the interaction effect.

Two locations are significant in the model, Washington D.C. and Las Vegas. Our fictitious candidate had a Washington, D.C. area code on the resume sent to employers, which we believe accounts for the higher callback rate for this location. As for Las Vegas, we only applied to nine jobs there, so it is difficult to speculate on callback rates with such a low number.

\footnotetext{
${ }^{2}$ In a separate model (available upon request), we clustered the analysis around the 22 job locations, and found substantively similar results.
} 


\section{DISCUSSION}

Following from research that has demonstrated stigmatizing attitudes associated with mental illness labels, we designed a study to test whether a history of mental illness evokes discrimination in the labor market. We applied to jobs in the software industry, varying applications by whether the individual had recently been hospitalized for a mental illness or a physical injury. We also varied whether we applied to positions that could be done mostly away from an office setting or were typical office positions. We found significant discrimination for candidates with a history of mental illness, and this discrimination did not differ for jobs that could be done away from an office setting.

Our findings contribute to the stigma tradition by documenting mental illness labels as leading to discrimination in a natural setting, representing the first study to do this in several decades and with a large sample size. Despite competitive credentials, and even though our fictitious candidate claims to be fully recovered, hirers were still reluctant to call back applicants who indicated they had been hospitalized for a mental illness. Had this discrimination differed between telecommuting and non-telecommuting positions, desire for social distance by hirers may have been an important factor leading to discrimination. That is, hirers may have been unwilling to hire applicants with mental illness due to fear of or aversion to interacting with the person face-to-face. However, the fact that this discrimination did not differ significantly for candidates who applied to telecommuting positions suggests that discrimination may have come more from diminished expectations of competence for the applicant with mental illness. Another explanation is that, even in the telecommuting conditions, hirers may have expected some inperson interaction with the candidate, and potentially drawn on negative stereotypes. . Krupa and colleagues (2009) demonstrated that workers may expect lower levels of competence from 
people with mental illness labels than other workers, in addition to other harmful stereotypes such as dangerousness or awkwardness. If this were true, the telecommuting conditions would have elicited similar, if possibly muted, levels of discrimination. Future research with a different indicator of anticipated future interactions would be valuable.

This study did not specifically test for the mechanisms undergirding labor market discrimination towards people with mental illness, however past research has shown that mental illness labels may evoke a wide range of damaging stereotypes that differ in degree of perceived competence/incompetence and warmth/dangerousness (Fiske et al. 2007; Sadler et al. 2012). For example, conditions such as schizophrenia or addictions were perceived as incompetent and not warm, while other conditions with symptoms such as anxiety or mood irregularities were perceived as moderate in both warmth and competence. Perceived dangerousness and violence is a particularly pervasive and damaging stereotype that has persisted for over half a century (Link et al. 1999; Phelan et al. 2000). People with disclosed mental illness labels, then, must overcome damaging stereotypes that may harm their chances of being hired even before an interaction can take place. Future research should assess the role of stereotypes in the stigma process for people with different mental health conditions, and the possibility for these stereotypes to be combated in meaningful interactions.

\section{Limitations}

This study only tested discrimination in the initial stage of the hiring process. Employers may in fact not discriminate against the mentally ill candidates once the person reaches the interview process. Nevertheless, our approach allows for a direct test of the effect of mental illness on hiring at the entry point of the labor market, thus providing direct evidence that a 
mental illness label alone may be sufficient to produce discrimination. While callback rates may appear low, two other studies of populations subject to public stigma reported callback rates of below 10\% (Kleykamp 2009; Tilcsik 2011).

Past audit studies have demonstrated the effects of other social characteristics on hiring, such as race, sexuality, and veteran status (Pager and Quillian 2005; Tilcsik 2011; Kleykamp 2009). Furthermore, research employing other methods has demonstrated that the gender of a person with mental illness may affect stigma toward them (Wirth and Bodenhausen 2009). Our study focused only on men, leaving race somewhat ambiguous, as an initial step to demonstrate that hiring discrimination exists in one setting based on mental illness. Future research should address gender, race, and age differences in hiring discrimination toward people with mental illness.

We utilized a labor market (software engineering) that was booming at the time we sent applications, and still is today. Moreover, as mentioned earlier, we believe our candidate was very well-qualified and would have appeared versatile to potential employers. Thus, apart from his history of mental health hospitalization, we expected him to appear very attractive to hirers. For this reason, we believe we created a scenario in which mental illness stigma should have been less likely than other labor market settings. However, we do not attempt to generalize to other types of labor markets, such as low-wage or less-skilled occupations. Rather, we have only demonstrated one setting in which mental illness stigma occurs in the initial stages of the hiring process.

We are uncertain how to interpret the non-finding on discrimination in telecommuting versus non-telecommuting jobs. We predicted that discrimination would be greater in non- 
telecommuting jobs because of an increased likelihood of those making callback decisions anticipating future interactions with the applicant if he was hired. This may be the case, but it may not. It is possible that for a substantial number of the positions, persons making callback decisions did not anticipate much interaction with applicants irrespective of whether the positions was or was not telecommuting.

We did not use a baseline condition for this study (with no past hospitalization). This is because we felt we had to provide a justification for an extended work absence to have equivalency between conditions. Even without a baseline condition, we feel we have an appropriate comparison group to highlight employment discrimination toward people with mental illness. However, as people with physical disabilities face discrimination (Ameri et al. 2015), our findings risked being biased toward finding support for the null hypothesis of no discrimination for people with mental illness.

\section{CONCLUSION}

Our study tested for the effect of a mental illness label without any indication of the applicant's personality or other behavioral characteristics. Some research has shown that stigmatization of individuals with a devalued characteristic may be reduced as a result of contact with others. For instance, Martinez et al. (2011) showed that normative interactions increased the degree to which people with mental illness were seen as human, thereby decreasing social rejection. Our study does not account for the behaviors of our candidate, and it may be the case that job applicants with mental illness increase their chances of being hired when they interact with employers. Future research should address this possibility. 
Mental illness labels, by evoking negative stereotypes and diminished expectations, may be detrimental to labeled individuals' life chances. Our research shows one social setting in which the stigma of mental illness may operate: the labor market. Despite identical qualifications, we found that a history of mental illness led to a significantly lower likelihood of an application being successful in eliciting a callback. Our study shows that the power of field experiments to illuminate social inequalities in large contexts otherwise impenetrable by social research can effectively be applied to the problem of discrimination against people with mental illness. The results we have presented demonstrate a valuable contribution to research on status loss and discrimination directed toward persons with mental illness, showing discriminatory effects of mental illness labels in a large work context. 


\section{REFERENCES}

Ameri, Mason, Lisa Schur, Meera Adya, Scott Bentley, Patrick McKay, Douglas Kruse. 2015. “The Disability Employment Puzzle: a Field Experiment on Employer Hiring Behavior." National Bureau of Economic Research Working Paper.

Baldwin, Marjorie L, and Steven C. Marcus. 2007. "Labor Market Outcomes of Persons with Mental Disorders." Industrial Relations: A Journal of Economy and Society 46(3):481510.

Berger, Joseph, Bernard P. Cohen, and Morris Zelditch, Jr. 1966. "Status Characteristics and Expectation States.” Pp. 29-46 in Joseph Berger, Morris Zelditch, Jr., and Bo Anderson (Eds.). Sociological Theories in Progress, Vol 1. Boston: Houghton Mifflin.

Berger, Joseph, Bernard P. Cohen, and Morris Zelditch, Jr. 1972. "Status Characteristics and Social Interaction.” American Sociological Review 37: 241-255.

Berger, Joseph, M. Hamit Fisek, and Robert Z. Norman. 1989. "The Evolution of Status Expectations: A Theoretical Extension.” Pp. 100-130 in Sociological Theories in Progress: New Formulations, edited by Joseph Berger, Morris Zelditch, Jr., and Bo Anderson. Newbury Park, CA: Sage.

Berger, Joseph, M. Hamit Fisek, Robert Z. Norman, and Morris Zelditch, Jr. 1977. Status Characteristics and Social Interaction: An Expectation States Approach. New York: Elsevier.

Bertrand, Marianne, and Sendhil Mullainathan. 2003. "Are Emily and Greg More Employable than Lakisha and Jamal? A Field Experiment on Labor Market Discrimination.” National Bureau of Economic Research 9873.

Brand, R. Curtis and William L. Claiborn. 1976. "Two Studies of Comparative Stigma: 
Employer Attitudes and Practices toward Rehabilitated Convicts, Mental and Tuberculosis Patients." Community Mental Health Journal 12: 168-75.

Cook, J. A. 2006. “Employment Barriers for Persons With Psychiatric Disabilities: Update of a Report for the President's Commission.” Psychiatric Services 57(10):1391-1405.

Corrigan, Patrick. 2000. "Mental Health Stigma as Social Attribution: Implications for Research Methods and Attitude Change." Clinical Psychology: Science and Practice 7: 48-67.

Corrigan, Patrick W. 2003. "Perceptions of Discrimination Among Persons With Serious Mental Illness." Psychiatric Services 54(8):1105-1110.

Druss, Benjamin G., Steven C. Marcus, Robert A. Rosenheck, Mark Olfson, Terri Tanielian and Harold A. Pincus. 2000. "Understanding Disability in Mental and General Medical Conditions." American Journal of Psychiatry 157: 485-91.

Farina, Amerigo and Ring. K. (1965). "The Influence of Perceived Mental Illness on Interpersonal Relations. Journal of Abnormal Psychology, 70(1),47-51.

Farina, Amerigo and R. D. Felner. 1973. "Employment Interviewer Reactions to Former Mental Patients." Journal of Abnormal Psychology 82: 268-72.

Fife, Betsy L., and Eric R. Wright. 2000. "The Dimensionality of Stigma: A Comparison of its Impact on the Self of Persons with HIV/AIDS and Cancer." Journal of Health and Social Behavior 41: 50-67.

Fiske, Susan T., Amy JC Cuddy, and Peter Glick. 2007. "Universal Dimensions of Social Cognition: Warmth and Competence." Trends in Cognitive Sciences 11(2): 77-83.

Goffman, Erving. (1963). Stigma: Notes on the management of spoiled identity. Englewood Cliffs, NJ: Prentice Hall.

Hebl Michelle R. and John F. Dovidio. 2005. "Promoting the 'Social' in the Examination of 
Social Stigmas." Personality and Social Psychology Review 9: 156-82.

Hebl, Michelle R., Jennifer Tickle and Todd F. Heatherton. 2000. “Awkward Moments in Interactions Between Non-Stigmatized and Stigmatized Individuals. Pp. 275-306 in The Social Psychology of Stigma, edited by T.F. Heatherton, R.E. Kleck, M.R. Hebl, and J.G. Hull. New York: Guilford.

Kleykamp, Meredith. 2009. A Great Place to Start? The Effect of Prior Military Service on Hiring. Armed Forces and Society, 35(2): 266-285.

Krupa, Terry, Bonnie Kirsh, Lynn Cockburn, and Rebecca Gewurtz. 2009. "Understanding the Stigma of Mental Illness in Employment." Work: A Journal of Prevention, Assessment, and Rehabilitation 33(4): 413-425.

Lauster, Nathanael, and Adam Easterbrook. 2011. "No Room for New Families? A Field Experiment Measuring Rental Discrimination against Same-Sex Couples and Single Parents." Social Problems 58(3):389-409.

Link, Bruce G. (1987). Understanding Labeling Effects in the Area of Mental Disorders: An Assessment of the Effects of Expectations of Rejection. American Sociological Review, $52,96-112$.

Link, Bruce, Francis Cullen, James Frank, and John F. Wozniak. 1987. "The Social Rejection of Former Mental Patients: Understanding Why Labels Matter." American Journal of Sociology 92: $1461-1500$.

Link, Bruce G., Francis T. Cullen, Elmer L. Struening, Patrick E. Shrout, and Bruce P. Dohrenwend 1989. "A Modified Labeling Theory Approach in the Area of Mental Disorders: An Empirical Assessment." American Sociological Review 54: 100-23. Link, Bruce G., Jo C. Phelan, M. Bresnahan, A. Stueve and Bernice A. Pescosolido. 1999. 
"Public Conceptions of Mental Illness: Labels, Causes, Dangerousness and Social Distance." American Journal of Public Health 89: 1328-1333.

Link, Bruce G. and Jo C. Phelan. 2001. "Conceptualizing Stigma.” Annual Review of Sociology 27: $363-85$.

Link, Bruce G., Lawrence H. Yang, Jo C. Phelan and Pamela Y. Collins. 2004. "Measuring Mental Illness Stigma." Schizophrenia Bulletin 30: 11-42.

Lucas, Jeffrey W. 2003. "Status Processes and the Institutionalization of Women as Leaders." American Sociological Review, 68: 464-480.

Lucas, Jeffrey W. and Jo C. Phelan. 2012. "Stigma and Status: The Interrelation of Two Theoretical Perspectives." Social Psychology Quarterly, 75, 310-333.

Martinez, Andres G., Paul K. Piff, Rodolfo Mendoza-Denton, and Stephen P. Hinshaw. 2011. "The Power of a Label: Mental Illness Diagnoses, Ascribed Humanity, and Social Rejection.” Journal of Social and Clinical Psychology 30(1):1-23.

Page, Stewart, and D Day. 1990. "Acceptance of the 'Mentally Ill' in Canadian Society: Reality and Illusion." Canadian Journal of Community Mental Health 9: 51-61.

Phelan, Jo C., Bruce G. Link, Ann Stueve, and Bernice A. Pescosolido. 2000. "Public Conceptions of Mental Illness in 1950 and 1996: What is Mental Illness and Is It to be Feared?." Journal of health and Social Behavior. 188-207.

Phelan, Jo C. 2005. "Geneticization of Deviant Behavior and Consequences for Stigma: The Case of Mental Illness." Journal of Health and Social Behavior 46: 307-322.

Phelan, Jo C., Bruce G. Link and John F. Dovidio. 2008. "Stigma and Prejudice: One Animal or Two?" Social Science and Medicine 67: 358-67.

Podolny, Joel M. 1993. "A Status-Based Model of Market Competition." American Journal of 
Sociology 98: 829-872.

Premeaux, Sonya F. 2001. "Impact of Applicant Disability on Selection: the Role of Disability Type, Physical Attractiveness, and Proximity.” Journal of Business and Psychology 16(2):291-298.

Ridgeway, Cecilia. 2001. “Gender, Status, and Leadership.” Journal of Social Issues 57(4): 637 655.

Ritsher, J Boyd, and Jo C. Phelan. 2004. "Internalized Stigma Predicts Erosion of Morale Among Psychiatric Outpatients." Psychiatry Research 129: 257-65.

Rosenfeld, Sarah. 1997. "Labeling Mental Illness: The Effects of Received Services and Perceived Stigma on Life Satisfaction.” American Sociological Review, 62, 660-672.

Sadler, Melody S., Elizabeth L. Meagor, and Kimberly E. Kaye. 2012. "Stereotypes of Mental Disorders Differ in Competency and Warmth.” Social Science and Medicine 74: 915922.

Sibicky, Mark and John F. Dovidio. 1986. "Stigma of Psychological Therapy: Stereotypes, Interpersonal Reactions, and the Self-Fulfilling Prophecy." Journal of Consulting and Clinical Psychology 33: 148-154.

Sirey, Jo Ann, Martha L. Bruce, George S. Alexopoulos, Deborah A. Perlick, Steven J. Friedman and Barnett S. Meyers. 2001. "Stigma as a Barrier to Recovery: Perceived Stigma and Patient-Rated Severity of Illness as Predictors of Antidepressant Drug Adherence." Psychiatric Services 52: 1615-20.

Stuart, Heather. 2004. "Stigma and Work." HealthcarePapers 5(2):100-111.

Tilcsik, Andras. 2011. "Pride and Prejudice: Employment Discrimination against Openly Gay Men in the United States." American Journal of Sociology 117(2):586-626. 
Weiner, Bernard, Raymond P. Perry, and Jamie Magnusson. 1988. "An Attributional Analysis of Reactions to Stigmas." Journal of Personality and Social Psychology 55: 738-748.

Wirth, James H., and Galen V. Bodenhausen. 2009. "The Role of Gender in Mental-Illness Stigma: A National Experiment.” Psychological Science 20(2): 169-173. 
Table 1. Number of Applications Sent by City

\begin{tabular}{lrr}
\hline City & $\mathrm{N}$ & \multicolumn{2}{c}{$\%$} \\
\hline San Francisco & 113 & 17.80 \\
Seattle & 59 & 9.29 \\
Washington, D.C. & 49 & 7.72 \\
New York City & 45 & 7.09 \\
Toronto & 43 & 6.77 \\
Boston & 34 & 5.35 \\
Denver & 34 & 5.35 \\
Chicago & 33 & 5.20 \\
Atlanta & 32 & 5.04 \\
Los Angeles & 31 & 4.88 \\
Portland & 26 & 4.09 \\
Dallas & 20 & 3.15 \\
Austin & 20 & 3.15 \\
Raleigh & 18 & 2.83 \\
San Diego & 14 & 2.20 \\
Miami & 13 & 2.05 \\
Houston & 11 & 1.73 \\
Philadelphia & 11 & 1.73 \\
Phoenix & 11 & 1.73 \\
Las Vegas & 9 & 1.42 \\
Montreal & 8 & 1.26 \\
San Antonio & 1 & 0.16 \\
Total & & \\
& 635 & 100.00
\end{tabular}


Table 2. Number of Callbacks by Applicant Characteristics and Type of Position ( $N=635)$

\begin{tabular}{|c|c|c|c|}
\hline Condition & $\mathbf{N}$ & \# Callbacks & $\%$ \\
\hline Mental Illness, Non-Telecommuting & 174 & 32 & 18.39 \\
\hline Mental Illness, Telecommuting & 150 & 16 & 10.67 \\
\hline Physical Injury, Non-Telecommuting & 162 & 40 & 24.69 \\
\hline Physical Injury, Telecommuting & 149 & 28 & 18.79 \\
\hline $\begin{array}{r}\text { Reason for Work Absence } \\
\end{array}$ & $\mathbf{N}$ & \# Callbacks & $\%$ \\
\hline Mental Illness & 324 & 48 & 14.81 \\
\hline Physical Injury & 311 & 68 & 21.86 \\
\hline
\end{tabular}

$* \mathrm{p}=.022$, two-tailed t-test 
Table 3. Logistic Regression Predicting the Odds of Receiving a Callback (N=615)

\section{Model 1}

Model 2

(No Interaction Effect)

(with Interaction Effect)

\begin{tabular}{|c|c|c|c|c|c|c|}
\hline & \multicolumn{2}{|c|}{ Odds Ratio } & St. Error & \multicolumn{2}{|l|}{ Odds Ratio } & \multirow{2}{*}{$\begin{array}{r}\text { St. Error } \\
0.174\end{array}$} \\
\hline Mentally Ill Applicant & 0.544 & $* *$ & 0.12 & 0.616 & & \\
\hline Telecommuting Job & 0.682 & & 0.156 & 0.782 & & 0.233 \\
\hline Mentally Ill Applicant X Telecommuting Job & --- & & --- & 0.729 & & 0.328 \\
\hline \# Days Between Post and Application & 0.882 & $*$ & 0.05 & 0.883 & $*$ & 0.05 \\
\hline \multicolumn{7}{|l|}{ Job Location $($ Reference $=$ San Francisco $)$} \\
\hline New York City & 0.719 & & 0.369 & 0.712 & & 0.364 \\
\hline Chicago & 1.886 & & 0.885 & 1.915 & & 0.911 \\
\hline Seattle & 1.187 & & 0.505 & 1.177 & & 0.501 \\
\hline Dallas & 0.53 & & 0.422 & 0.529 & & 0.421 \\
\hline Washington, DC & 3.276 & $* *$ & 1.304 & 3.271 & $* *$ & 1.301 \\
\hline Los Angeles & 0.731 & & 0.438 & 0.724 & & 0.434 \\
\hline Toronto & 0.664 & & 0.361 & 0.652 & & 0.355 \\
\hline Houston & 0.53 & & 0.578 & 0.552 & & 0.603 \\
\hline Atlanta & 0.71 & & 0.425 & 0.71 & & 0.425 \\
\hline Las Vegas & 4.553 & $*$ & 3.393 & 4.511 & $*$ & 3.38 \\
\hline Boston & 1.265 & & 0.638 & 1.258 & & 0.635 \\
\hline Austin & 1.288 & & 0.801 & 1.244 & & 0.777 \\
\hline San Diego & 3.183 & & 1.986 & 3.176 & & 1.98 \\
\hline Portland & 1.216 & & 0.69 & 1.233 & & 0.7 \\
\hline Miami & 0.812 & & 0.666 & 0.832 & & 0.684 \\
\hline Denver & 0.477 & & 0.315 & 0.475 & & 0.314 \\
\hline Raleigh & 1.42 & & 0.892 & 1.392 & & 0.88 \\
\hline Phoenix & 1.117 & & 0.928 & 1.113 & & 0.925 \\
\hline LR chi2 & 43.85 & $* *$ & & 44.35 & $* *$ & \\
\hline
\end{tabular}

$* \mathrm{p}<.05 ; * * \mathrm{p}<.01$ 